\title{
Ingrid A. R. De Smet, "Thuanus". The Making of Jacques-Auguste de Thou (1553-1617)
}

\section{Dario Cecchetti}

\section{(2) OpenEdition}

12 Journals

\section{Edizione digitale}

URL: http://journals.openedition.org/studifrancesi/9481

DOI: $10.4000 /$ studifrancesi.9481

ISSN: 2421-5856

\section{Editore}

Rosenberg \& Sellier

\section{Edizione cartacea}

Data di pubblicazione: 1 décembre 2007

Paginazione: 641

ISSN: 0039-2944

\section{Notizia bibliografica digitale}

Dario Cecchetti, «Ingrid A. R. De Smet, "Thuanus". The Making of Jacques-Auguste de Thou (1553-1617)», Studi Francesi [Online], 153 (LI | III) | 2007, online dal 30 novembre 2015, consultato il 10 janvier 2021. URL: http://journals.openedition.org/studifrancesi/9481; DOI: https://doi.org/10.4000/studifrancesi. 9481

Questo documento è stato generato automaticamente il 10 janvier 2021.

\section{(c)}

Studi Francesi è distribuita con Licenza Creative Commons Attribuzione - Non commerciale - Non opere derivate 4.0 Internazionale. 


\title{
Ingrid A. R. De Smet, "Thuanus". The Making of Jacques-Auguste de Thou (1553-1617)
}

\author{
Dario Cecchetti
}

\section{NOTIZIA}

INGRID A. R. DE SMET, “Thuanus”. The Making of Jacques-Auguste de Thou (1553-1617), Genève, Droz, 2006 («Travaux d'Humanisme et Renaissance», n. CDXVIII), pp. 347.

1 Quest'ampia monografia offre una ricostruzione accurata della vita di Jacques-Auguste de Thou e uno studio sistematico della sua produzione, anche in quegli aspetti oggi dimenticati ma che lo resero celebre al suo tempo. Se infatti la fama postuma, a tutt'oggi, si fonda sulla sua produzione di storico e apologeta (per la prima, citiamo le Historiae sui temporis, per la seconda, la Vita), la vastissima produzione di poeta neolatino (valga l'esempio dello Hieracosophion, del poema Iobus sive de constantia o del Carminum liber) non solo godette di grande fama, ma servì a de Thou per tessere una rete di rapporti nel mondo della politica come in quello della cultura (interessante a questo riguardo il capitolo I: «Going Public: Rewriting and Self-Fashioning», pp. 51-73). In questa rete di rapporti vengono evidenziati quelli con Scaligero, Giusto Lipsio e Isaac Casaubon, vero triumvirato del tardo Umanesimo, ai quali de Thou viene accostato, con un'illustrazione puntuale delle strette connessioni (capitolo II: «The Fourth Man? De Thou and the Republic of Letters», pp. 75-105), e con un'attenzione particolare a ricostruire oltre ai legami intellettuali fra pari, i legami formativi sul piano delle conoscenze personali e sul piano delle letture e degli studi (capitolo IV: «...l'hostel où Platon et Aristote ont esleu domicile», pp. 147-200). Il volume di I.A.R. De Smet nel disegnare un panorama della produzione di de Thou, che si intreccia con la ricostruzione di una carriera che è a un tempo politica e intellettuale, mette in evidenza le strategie di 'potere' messe in atto da grande umanista per costruirsi una posizione di primo piano, sulle orme del padre, Christophe de Thou, primo presidente 
del Parlamento di Parigi. Queste strategie comportano non solo la tessitura di una rete di rapporti intellettuali, ma una calcolata politica matrimoniale e di scelte parentali, il cui studio (capitolo III: «De Thou's Women: of Politics, Poetry and Procreation», pp. 107-145) offre un'interessante esemplificazione dei meccanismi di potere all'interno dell'alta noblesse de robe, implicata nella complicata politica dell'epoca che va dalle guerre di religione al regno di Henri IV. Ciò che de Thou, malgrado il succedersi negli anni di prestigiosi incarichi, sentì come fallimento politico - la mancata nomina a primo presidente del Parlamento parigino - fu rielaborato e memorizzato nelle sue opere storiche e memorialistiche sotto il manto del neostoicismo, il che inserisce una figura complessa di poeta, storico e politico nel quadro di una precisa corrente spirituale e intellettuale che si dipana in Francia a partire da Montaigne (capitolo V: «Thuanus Bifrons? De Thou and the History of His Own Times», pp. 201-261, e «Conclusion. The Final Years», pp. 263-285). Sono questi i punti affrontati da un'indagine estremamente ricca e stimolante che tiene fede al proposito iniziale di rispondere alla domanda «di come de Thou riuscì a costruire una personalità di intellettuale e di uomo politico in un'epoca (quella degli sconvolgimenti delle guerre di religione) in cui l'identità della sua classe sociale e professionale era profondamente minacciata; rispondere alla domanda di quali furono i meccanismi (sociali, politici, intellettuali e personali) che funzionarono da propellente o da ostacolo alla sua ascesa; rispondere alla domanda, infine, di cosa significò per de Thou - come per i suoi contemporanei - il fatto di essere figlio, marito e padre, oltre che persona socialmente di rilievo» (p. 18). 